\title{
The Differences between the Effects of a Nanoformulation and a Conventional Form of Atrazine to Lettuce: Physiological Responses, Defense Mechanisms, and Nutrient Displacement
}

Juan Wu, Yujia Zhai,* Fazel Abdolahpur Monikh, Daniel Arenas-Lago, Renato Grillo, Martina G. Vijver, and Willie J. G. M. Peijnenburg*

Cite This: J. Agric. Food Chem. 2021, 69, 12527-12540

Read Online

ABSTRACT: The rapid development of nanotechnology influences the developments within the agro-sector. An example is provided by the production of nanoenabled pesticides with the intention to optimize the efficiency of the pesticides. At the same time, it is important to collect information on the unintended and unwanted adverse effects of emerging nanopesticides on nontarget plants. Currently, this information is limited. In the present study, we compared the effects of a nanoformulation of atrazine (NPATZ) and the nonencapsulated atrazine formulation (ATZ) on physiological responses, defense mechanisms, and nutrient displacement in lettuce over time with the applied concentrations ranging from 0.3 to $3 \mathrm{mg}$ atrazine per $\mathrm{kg}$ soil. Our results revealed that both NPATZ and ATZ induced significant decreases in plant biomass, chlorophyll content, and protein content. Additionally, exposure to NPATZ and ATZ caused oxidative stress to the lettuce plant and significantly elevated the activities of the tested ROS scavenger enzymes in plant tissues. These results indicate that NPATZ and ATZ cause distinct adverse impacts on lettuce plants. When comparing the adverse effects in plants after exposure to NPATZ and ATZ, no obvious differences in plant biomass and chlorophyll content were observed between NPATZ and ATZ treatments at the same exposure concentration regardless of exposure duration. An enhanced efficiency of the active ingredient of the nanopesticide as compared to the conventional formulation was observed after long-term exposure to the high concentration of NPATZ, as it induced higher impacts on plants in terms of the end points of the contents of protein, superoxide anion $\left(\mathrm{O}_{2}^{-}\right)$, and $\mathrm{MDA}$, and the activities of stress-related enzymes as compared to the same concentration of ATZ. Furthermore, exposure to both NPATZ and ATZ disrupted the uptake of mineral nutrients in plants, and the differences in the displacement of nutrients between the NPATZ and ATZ treatments depended on the element type, plant organ, exposure concentration, and time. Overall, the application dose of a nanopesticide should balance their increased herbicidal efficiency with the long-term adverse effects in order to maximize the desired impact while minimizing adverse impacts; only then will we be able to understand the potential impact of nanopesticides on the environment.

KEYWORDS: nanopesticide, herbicide, nontarget plant, oxidative stress, phytotoxicity

\section{INTRODUCTION}

Atrazine is a common herbicide of the triazine class, and is the second most popular herbicide applied in the world to control weeds and to promote agricultural productivity with low $\operatorname{cost}^{1,2}$. Although its application has been banned in the European Union since October 2003 because of its side effects on nontarget organisms and human health, ${ }^{3}$ it is still in use in some countries, including the United States, Australia, Brazil, and China. ${ }^{4,5}$ The atrazine market is expected to register a CAGR of $6 \%$ from 2019 to 2024 and will reach USD 2.58 billion by the end of $2024 .^{6}$ Nevertheless, the long half-life of atrazine means that atrazine is retained in soil for a long time. ${ }^{7}$ This may cause harmful effects to nontarget organisms in soil, contaminate the environment, and disrupt the ecosystem.

The rapid development of nanotechnology opens up promising avenues to sustainable applications, also in agriculture, with particular attention in producing nanoformulations of pesticides. ${ }^{8-10}$ Claims are that the nanofeatures may overcome unwanted emissions to nontarget sites and the organisms living therein. To compare, the effectiveness of the traditional (non-nanoformulation) herbicides is notoriously low as less than $0.1 \%$ of the applied herbicides typically reaches the target organisms (site). ${ }^{11,12}$ Recently, nanoencapsulation technology has been used as a carrier system to modify atrazine to achieve greater efficiency. ${ }^{13-15}$ The enlarged surface-to-volume area leads to higher adsorption to target crops. Furthermore, nanopesticides exhibit higher stability and allow the control of the release and distribution of the active ingredient to the target specifically, ${ }^{16-18}$ as well as extend their duration of action by protecting against untimely degradation of the active ingredient. ${ }^{19}$ Because of these features, the applied dosage and frequency of pesticide use may be reduced, thus avoiding unwanted emissions by drift,

Received: March 8, 2021

Revised: September 17, 2021

Accepted: October 4, 2021

Published: October 18, 2021 
runoff, or leaching, and minimizing pollution and risk to the environment. ${ }^{20}$ These are promising features for reducing risks, but nonetheless, it is important to evaluate the effects of nanopesticides to nontarget edible plants and organisms for those cases that the nanoformulations do reach the nontarget sites. $^{10}$ As more and more nanoenabled pesticides are emerging, understanding the differences between conventional- and nanoformulations is crucial as "green and clean" claims should be underpinned before their large-scale application in agriculture. That means not only compare the concentrations of nano or non-nano pesticides in the ecotoxicity tests, but also taking into account the higher pesticide efficacy of the nanopesticides to their conventional ones.

The common mode of action of conventionally applied atrazine to control weed growth is to inhibit the photosynthesis process by blocking the electron transfer chain in photosystem II (PSII), thus resulting in weed leaf chlorosis and necrosis. $^{21,22}$ Exposure to atrazine can additionally induce the extensive accumulation of reactive oxygen species (ROS), which can lead to oxidative stress and may result in cell damage, such as lipid peroxidation, membrane damage, and overall metabolism imbalance, and even plant death. ${ }^{23}$ There are a great number of studies which reported that pure atrazine generates toxic effects to nontarget organisms, for example, plants, soil microorganisms, and even aquatic species with a common result of oxidative damage. ${ }^{17,22,24,25}$ However, the information regarding the oxidative damage of a nanoformulation of atrazine using nanoencapsulation as a shell to nontarget plants after long-term exposure is very limited, and the oxidative damage could be changed by the nanoscale formulation. After all, some generic studies on nanomaterials describe their higher oxidative stress responses induced by colloidal stress. ${ }^{26}$ To date, current studies about the nanoformulation of atrazine have focused on basic physiological responses, for example, seed germination, root or shoot elongation, and the reduction of biomass. ${ }^{27,5}$ Since oxidative stress is a typical consequence of atrazine toxicity, a common analysis of antioxidative defense processes and physiological indicators offer comprehensive information. Also, atrazine delivery system may influence the photosynthetic systems of nontarget plants. ${ }^{28}$ Additionally, the oxidative stress and the changes of the photosynthetic process in plants may disrupt nutrient uptake, which would dramatically affect the growth and development of plants. ${ }^{29}$ More specifically, vegetables are the major source for human beings' intake of several nutrients, for example, $\mathrm{Fe}$ and $\mathrm{Zn}$, which are of importance for human health. Therefore, it is critical to assess whether the use of nanoatrazine would affect the mineral nutritional quality of nontarget plants.

In this study, a nanoformulation of atrazine was synthesized using poly- $\varepsilon$-caprolactone as the biodegradable polymeric carrier (atrazine is encapsulated in the nanosized polymeric nanocapsules) and their toxicity to nontarget plants was investigated. Lettuce, a widely cultivated and the most consumed vegetable worldwide and usually used in contaminant toxicity studies, was used as model plant in this study. The objective of this study is to compare the effects of different concentration of the nanoformulated and traditional atrazine on the physiological responses, defense mechanisms, and nutrient displacement in a nontarget plant over time. So this will shed light on whether the application of nanopesticides will impact the energy/nutrients supply of plants as a diet.
Lettuce (Lactuca sativa), was exposed to pure atrazine (ATZ) and the nanoencapsulated atrazine (NPATZ) at nominal concentrations of $0.3,1.5$, and $3 \mathrm{mg} / \mathrm{kg}$, and poly- $\varepsilon$ caprolactone nanocapsules (NPC-negative control) following different exposure durations. Also, the content of chlorophyll pigments was determined to study the impact of NPATZ on photosynthesis. Additionally, ROS production and the activities of ROS scavenger enzymes were quantified. Furthermore, the nutrients concentrations in lettuces were measured to assess whether the application of nanoatrazine induces nutrients deficiency in crops.

\section{MATERIALS AND METHODS}

2.1. Synthesis and Characterization of Nanoformulation of Atrazine. Atrazine (ATZ) loaded poly caprolactone nanocapsules (NPATZ) were synthesized according to the method reported by Grillo et al., ${ }^{13}$ as described in Supporting Information SI) S1. Briefly, $100 \mathrm{mg}$ of polycaprolactone nanocapsules (NPC) and $10 \mathrm{mg}$ of atrazine were first mixed in $30 \mathrm{~mL}$ of acetone containing Myritol 318 and Span 60 under magnetic stirring at $40{ }^{\circ} \mathrm{C}$ as the organic phase and then $30 \mathrm{~mL}$ of $2 \mathrm{mg} / \mathrm{mL}$ of polysorbate 80 (Tween 80 , as aqueous phase) was added into the mixture of NPC and atrazine (the organic phase). Afterward, the nanocapsule of atrazine formed when the organic solution and aqueous solution were mixed slowly via the insertion of the organic phase over the aqueous phase. Finally, the acetone and water were evaporated to make the nanoformulation contain $1 \mathrm{mg} / \mathrm{mL}$ of atrazine. The morphology and size distribution of the NPATZs were measured. The size distribution of NPATZ measured by SEM was around $100 \mathrm{~nm}$. The hydrodynamic size and zeta potential of the NPATZ was $120 \pm 10 \mathrm{~nm}$ and $-28 \pm 4 \mathrm{mV}$, respectively. The time to release $50 \%$ of ATZ from NPATZ was 11.5 $\mathrm{h}$, and the concentration of ATZ in the supernatant of the filtrate of NPATZ-spiked soil after centrifugation was significantly lower compared to the concentration of ATZ in the supernatant of ATZspiked soil. The detailed results of the characterizations and release kinetics assays of NPATZ are published in our previous publication ${ }^{18}$ and given in SI S1 and S2.

2.2. Soil Collection and Plant Growth. A sandy loam soil, obtained from a clean area $\left(52^{\circ} 10^{\prime} 16.8^{\prime \prime} \mathrm{N} 4^{\circ} 26^{\prime} 58.9^{\prime \prime} \mathrm{E}\right.$, Leiden, Netherlands, top $0-10 \mathrm{~cm}$, no atrazine was detected), was sampled, air-dried, sieved with an $8 \mathrm{~mm}$ sieve, and kept at $4{ }^{\circ} \mathrm{C}$ before use. The physicochemical properties of the soil are given in SI S3. Lactuca sativa seeds (Floveg GmbH, Kall, Germany) were first sterilized in $0.5 \%(\mathrm{w} / \mathrm{v}) \mathrm{NaClO}$ for $5 \mathrm{~min}$ and then rinsed three times with tap water. After immersing in deionized water for $24 \mathrm{~h}$, the seeds were germinated in a Petri dish filled with a wet filter paper ( 15 seedlings/ dish). After gemination, the seedlings were pregrown hydroponically with $1 / 4$ Hoagland solution $^{30}$ for 2 weeks, and the nutrient solution was refreshed every 3 days. The composition of the nutrient solution is described in SI S4. Afterward, the uniform pregrown seedlings were transferred into plastic pots $(9 \mathrm{~cm}$ in length, $9 \mathrm{~cm}$ in wide, $9.5 \mathrm{~cm}$ in high) containing $0.5 \mathrm{~kg}$ of soil for further 2 weeks of growth. The plants for the experiment were grown at $20 / 16{ }^{\circ} \mathrm{C}$ day (16h light) $/$ night ( $8 \mathrm{~h}$ dark) temperature and $60 \%$ relative humidity until harvest.

2.3. Experimental Design. Plants were exposed to ATZ and NPATZ at the same nominal concentrations (nominal concentrations are expressed as ATZ content in the case of the nanoformulation) of $0.3,1.5$, or $3 \mathrm{mg}$ atrazine per $\mathrm{kg}$ soil, representing a low concentration (ATZ-L, NPATZ-L), the recommended concentration ${ }^{31}$ (ATZ-M, NPATZ-M), and a high exposure concentration (ATZ-H, NPATZ$\mathrm{H})$ for ATZ, respectively. The polymeric nanocapsules without ATZ (NPC) as controls and blank controls (water only with the equivalent volume as used for the other treatments) were performed under the same conditions. The measured concentrations of atrazine at shortterm exposure for low, medium, and high exposure concentrations were $0.27 \pm 0.04,1.69 \pm 0.2$, and $3.2 \pm 0.3 \mathrm{mg} / \mathrm{kg}$ of soil in the ATZ treatments and $0.25 \pm 0.4,1.38 \pm 0.6$, and $2.7 \pm 0.5 \mathrm{mg} / \mathrm{kg}$ of soil in the NPATZ treatments, respectively. 
To prepare the ATZ stock suspensions, ATZ was first dissolved in $5 \mathrm{~mL}$ of acetone and subsequently diluted with Milli-Q water to obtain the selected concentrations. Subsequently, the prepared suspensions of NPATZ, ATZ, and NPC were sonicated for $15 \mathrm{~min}$ at $60 \mathrm{~Hz}$ (USC200T, VWR, Amsterdam, The Netherlands). After the sonication, the suspensions were continuously stirred with a mixer to maintain their homogeneity before adding into soil. To spike the soil, specific amounts of ATZ or NPATZ were carefully and dropped into the soil in order to obtain the desired concentrations of ATZ. The exposure of the formulations at each concentration was carried out with three independent repetitive exposure durations at a two-week interval (week 2, 4, and 6 after exposure), representing a short-term, medium-term, and long-term exposure. In total, 24 treatments were set up in triplicate ( 72 pots in total) and each pot contained three individual plants, yielding nine plants per treatment. The pots were watered every 2 days and $10 \mathrm{~mL}$ of $1 / 4$ Hoagland solution was added into the soil every 6 days. The plants in each pot were harvested after each exposure duration (2, 4, and 6 weeks) and washed with flowing deionized water and ultrapure water three times, respectively. After air-drying, the plants were separated into the root and shoot to weigh their fresh biomass. Afterward, the plant root and shoot were frozen in liquid nitrogen and stored at $-80{ }^{\circ} \mathrm{C}$ until further analysis.

2.4. Pigment Content and ROS Production Measurement. Leaves $(0.1 \sim 0.2 \mathrm{~g})$ were homogenized in liquid nitrogen and extracted with $80 \%$ acetone for $24 \mathrm{~h}$ at $4{ }^{\circ} \mathrm{C}$ in the dark. Afterward, the extracts were centrifuged for $10 \mathrm{~min}$ at $4500 \mathrm{~g}$ at $4{ }^{\circ} \mathrm{C}$. Finally, chlorophyll $\mathrm{a}$ and $\mathrm{b}$ (chla, chlb), and carotenoids (car) were determined by measuring the absorbance at 663,646 , and $470 \mathrm{~nm}$, respectively. The concentrations of chla, chlb, and carotenoids were calculated according to Lichtenthaler and Wellburn: ${ }^{32}$

$$
\begin{aligned}
& C_{\mathrm{a}}=\frac{12.21 \times A_{663}-2.81 \times A_{646}}{M_{\text {plant }}} \\
& C_{\mathrm{b}}=\frac{20.13 \times A_{646}-5.03 \times A_{663}}{M_{\text {plant }}} \\
& C_{\mathrm{car}}=\frac{1000 \times A_{470}-3.27 \times C_{\mathrm{a}}-104 \times C_{\mathrm{b}}}{229 \times M_{\text {plant }}}
\end{aligned}
$$

For ROS production measurement, the separated plant roots/ shoots from the same pot were combined and considered as a replicate. The combined root tissues or shoot tissues were cut into small pieces and mixed thoroughly. Afterward, the plant root or shoot samples used for ROS analysis were selected randomly from these tissues. The superoxide anion $\left(\mathrm{O}_{2}^{-}\right)$assay in plant tissues from each treatment was executed according to the method of Wang and Lou ${ }^{33}$ with a modification. Leaf or root tissues (about $0.1 \mathrm{~g}$ ) were homogenized in ice-cold $50 \mathrm{mM}$ phosphate buffer ( $\mathrm{pH} 7.8$ ), and the extracts were centrifuged at a rate of $10000 \mathrm{~g}$ for $20 \mathrm{~min}$ at $4{ }^{\circ} \mathrm{C}$. Afterward, the supernatant $(\sim 0.5 \mathrm{~mL})$ was mixed with $0.9 \mathrm{~mL}$ of 50 $\mathrm{mM}$ potassium phosphate buffer $(\mathrm{pH} 7.8)$ and $0.10 \mathrm{~mL}$ of $10 \mathrm{mM}$ hydroxylamine hydrochloride, and incubated at $25{ }^{\circ} \mathrm{C}$ for $30 \mathrm{~min}$. Subsequently, $17 \mathrm{mM}$ sulphanilamide and $7 \mathrm{mM}$ a-naphthylamine were added orderly to the above reaction mixture, with a ratio of $1: 1: 1$ and the mixture was further kept at $25^{\circ} \mathrm{C}$ for $20 \mathrm{~min}$. The absorbance of the mixture was measured at $530 \mathrm{~nm}$, and the content of $\mathrm{O}_{2}^{-}$was quantified based on a standard curve $\left(\mathrm{O}_{2}^{-}\right.$content ranging from 0 to $10 \mu \mathrm{g}$ ) using $\mathrm{NaNO}_{2}$ as a reference (SI Figure $\mathrm{S} 1 \mathrm{~A}, R^{2}=0.99$ ).

Hydrogen peroxide $\left(\mathrm{H}_{2} \mathrm{O}_{2}\right)$ was quantified according to Mosa et al. $^{34}$ by homogenizing the plant tissues $(\sim 0.15 \mathrm{~g})$ with $2 \mathrm{~mL}$ precooled trichloroacetic acid (TCA, $0.1 \% \mathrm{~W} / \mathrm{V}$ ) and incubating the plant extracts with $1 \mathrm{M}$ potassium iodide. The content of $\mathrm{H}_{2} \mathrm{O}_{2}$ in the extracts was recorded at $390 \mathrm{~nm}$ spectrophotometrically and calculated based on a $\mathrm{H}_{2} \mathrm{O}_{2}$ standard curve with the concentration ranging from 0 to $0.1 \mu \mathrm{mol}$ (SI Figure S1B, $R^{2}=0.97$ ).

To analyze the lipid peroxidation of plants, the malondialdehyde (MDA) content in the plants was measured following the method of Mosa et al. ${ }^{34}$ by homogenizing the plant tissues $(\sim 0.15 \mathrm{~g})$ with $2 \mathrm{~mL}$ precooled trichloroacetic acid (TCA, $0.1 \% \mathrm{~W} / \mathrm{V})$. After centrifugation
( $10000 \mathrm{~g}$ for $15 \mathrm{~min}$ at $4{ }^{\circ} \mathrm{C}$ ), the supernatant of the extract was mixed with $0.5 \%$ thiobarbituric acid in $20 \%$ trichloroacetic acid (w/v) and further incubated for $30 \mathrm{~min}$ at $95{ }^{\circ} \mathrm{C}$, followed by quickly cooling in an ice bath and centrifugation at $10000 \mathrm{~g}$ for $15 \mathrm{~min}$. The absorbance of the sequent solution was recorded by a multiwell spectrophotometer at 450,532 , and $600 \mathrm{~nm}$ after centrifugation for $15 \mathrm{~min}$ at $10000 \mathrm{~g}$

2.5. Assays for Total Protein and Antioxidant Enzyme Activity. The preparation and selection of plant samples for the analysis of enzymes activity were the same as the methods used for ROS analysis. Roots or leaves tissues $(0.1 \sim 0.2 \mathrm{~g})$ were first ground in liquid nitrogen and then extracted with ice-cold $50 \mathrm{mM}$ phosphate buffer ( $\mathrm{pH}$ 7.8) including $1 \mathrm{mM}$ EDTA and $1 \%(\mathrm{~W} / \mathrm{V})$ polyvinylpyrrolidone by vibrationally using a mixer. After centrifugation at $10000 \mathrm{~g}$ for $20 \mathrm{~min}\left(4^{\circ} \mathrm{C}\right)$, the supernatant of each treatment was used to determine the content of protein and the activity of antioxidant enzymes. The protein content in each supernatant was determined based on the Coomassie brilliant blue G-250 dye-binding method by recording the absorbance spectrophotometrically at 525 $\mathrm{nm}$ and using Bovine serum albumin to build a standard curve. ${ }^{29}$ The activity of superoxide dismutase (SOD) was determined based on its capacity to inhibit the photochemical reduction of nitro blue tetrazolium (NBT) to generate the blue formazan, which has a maximum absorbance at $560 \mathrm{~nm}$. One unit of SOD activity was defined as the amount of enzyme causing 50\% inhibition of the photoreduction of NBT. ${ }^{29}$ The ascorbate peroxidase (APX) activity was spectrophotometrically quantified on the basis of the ability of APX to oxidize ascorbate acid after adding hydrogen peroxide by monitoring the decrease of absorbance at $290 \mathrm{~nm}$ for 3 min. $^{29}$ As Catalase (CAT) catalyzes the decomposition of $\mathrm{H}_{2} \mathrm{O}_{2}$, its activity was assayed by measuring the change of absorbance at $240 \mathrm{~nm}$ as a result of the consumption of $\mathrm{H}_{2} \mathrm{O}_{2}{ }^{29}$ The Polyphenol oxidase (PPO) activity was spectrophotometrically measured at $410 \mathrm{~nm}$ for 3 min on the basis of its ability to oxidize catechol, in a reaction mixture including enzyme extract, $50 \mathrm{mM}$ phosphate buffer $(\mathrm{pH} \mathrm{7)}$ and 10 $\mathrm{mM}$ catechol. ${ }^{29}$ The activity of peroxidase (POD) was assayed following the method of $\mathrm{Ma}$ et al. ${ }^{29}$ by catalytic oxidizing guaiacol with hydrogen peroxide and recording the changes of absorbance at $470 \mathrm{~nm}$ for $2 \mathrm{~min}$. The glutathione S-transferase (GST) activity was assessed according to the method of $\mathrm{Ma}$ et $\mathrm{al}^{29}$ by recording the formation of 1-glutathione-2,4-dinitrobenzene deriving from the conjugation of GSH with 1-chloro-2,4-dinitrobenzene (CDNB) at $340 \mathrm{~nm}$ for $5 \mathrm{~min}$. More detailed information about the biochemical parameters methodology and quantifications can be found in SI S5.

2.6. Quantification of Macro-and Micronutrients in Plants. Besides the protein content (see Section 2.5), we mainly determined the mineral nutrients like $\mathrm{K}$ and $\mathrm{Mg}$ (recommended dietary allowance $(\mathrm{RDA})>200 \mathrm{mg} /$ day), and the essential trace elements like $\mathrm{Fe}, \mathrm{Mn}$, $\mathrm{Zn}$ in plants to reflect the ability of nutrient supply of plants. The plant tissues of each treatment for the element analysis were washed in the order of $10 \mathrm{mM} \mathrm{HNO}_{3}, 10 \mathrm{mM}$ EDTA , and Milli-Q water to remove the attached metal ions. Afterward, root and shoot tissues were oven-dried at $70{ }^{\circ} \mathrm{C}$ for $72 \mathrm{~h}$ and their dry weight was recorded. The root and shoot samples were digested with $3 \mathrm{~mL}$ of $\mathrm{HNO}_{3}(65 \%)$ at $120{ }^{\circ} \mathrm{C}$ for $40 \mathrm{~min}$ on a hot plate and then $1.5 \mathrm{~mL}$ of $\mathrm{H}_{2} \mathrm{O}_{2}(30 \%)$ was added followed by heating for another $20 \mathrm{~min}$ to ensure complete digestion. ${ }^{29}$ After cooling to room temperature, all digests were diluted with deionized water, and their metal content was analyzed by inductively coupled plasma mass spectroscopy (ICP-MS). The nutrients translocation factor (TF) of nutrients from plant roots to plant shoots was calculated as follows: $\mathrm{TF}=$ concentration of nutrient in plant shoot $(\mathrm{mg} / \mathrm{kg}) /$ concentration of nutrient in plant root $(\mathrm{mg} /$ $\mathrm{kg})$.

2.7. Statistical Analysis. Statistically significant differences for the same end point among different treatments (controls, ATZ and NPATZ) under the same exposure duration were analyzed by means of one-way ANOVA followed by Duncan's honestly significant difference tests at $\alpha<0.05$ using IBM SPSS Statistics 25 (no deviations of data were found for normal distribution and homogeneity of variance with Shapiro-Wilk test and Bartlett test 

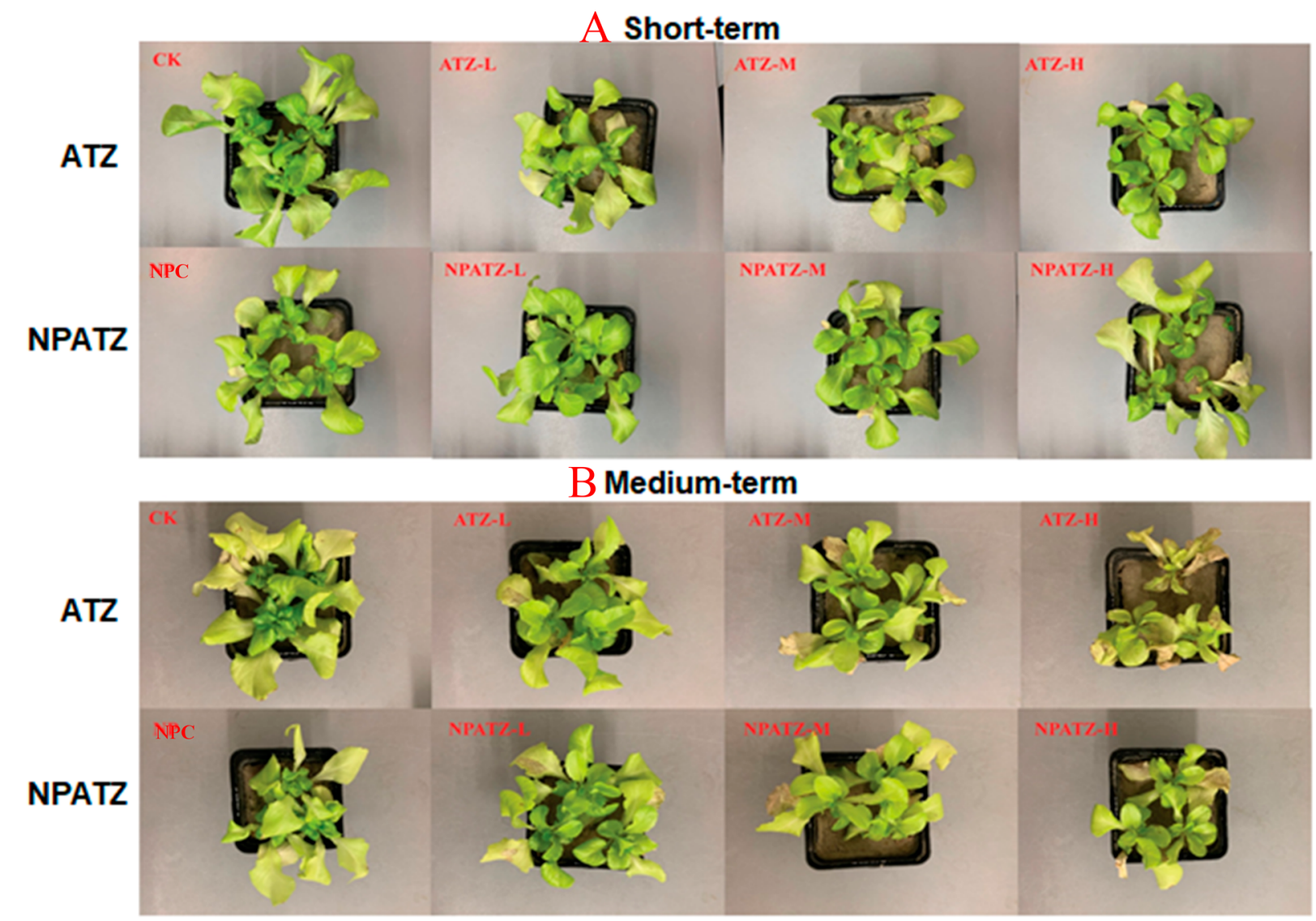

\section{Long-term}

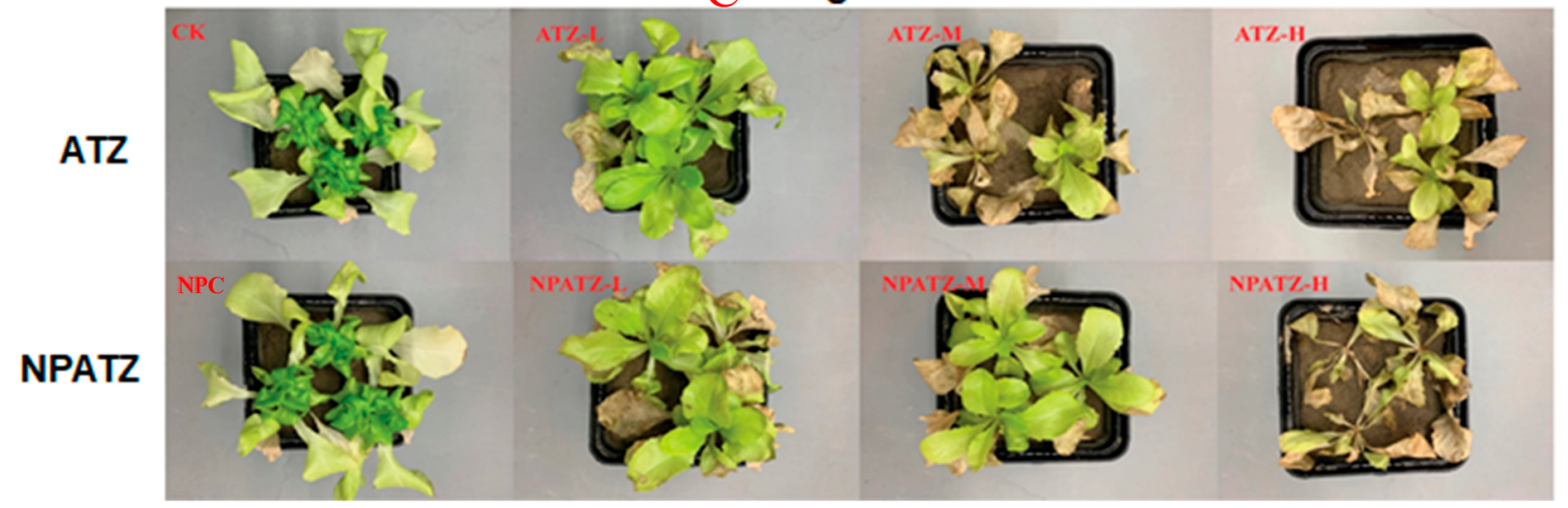

Figure 1. Growth of L. sativa in response to NPATZ and ATZ with concentrations ranging from low, medium, to high in short-term, medium-term, and long-term exposure durations. CK: control check, control plants without exposure to chemicals. NPC: exposure to a polymeric carrier without the ATZ (control). NPATZ-L: exposure to a low concentration of NPATZ. NPATZ-M: exposure to a medium concentration of NPATZ. NPATZ$\mathrm{H}$ : exposure to a high concentration of NPATZ. ATZ-L: exposure to a low concentration of ATZ. ATZ-M: exposure to a medium concentration of ATZ. ATZ-H: exposure to a high concentration of ATZ.

prior to running the ANOVA). Results are expressed as mean \pm standard error of nine replicates for biomass and three replicates for biochemical parameters and elemental analysis.

\section{RESULTS}

3.1. Plant Developmental Response. The effects of ATZ and NPATZ on plant development are given in Figure 1. In short-term exposure, the plants grow well in both ATZ and NPATZ treatments (Figure 1A). The first macroscopic symptoms of ATZ and NPATZ toxicity were observed after medium-term exposure, with leaf wilt in the high concentration of both ATZ and NPATZ (Figure 1B). In the long term exposure, plant development was affected in the medium concentration of ATZ and NPATZ. In the long term exposure of high concentrations of ATZ and NPTAZ, the plants growth revealed similar symptoms of leaf wilt, yellowing, and necrosis.

The effects of ATZ and NPATZ on the shoot and root biomass along with exposure time are given in Figure $2 \mathrm{~A}-\mathrm{C}$. In short-term exposure, significant decreases in shoot biomass were observed in the exposure of ATZ-M and ATZ-H (shoot biomass decreased from 1.24 to $0.80 \mathrm{~g}$ and from 1.24 to $0.85 \mathrm{~g}$, respectively) and NPATZ-H (shoot biomass decreased from 1.24 to $0.79 \mathrm{~g}$ ) (Figure $2 \mathrm{~A}$ ), but no significant decreases in root biomass were observed for all treatments in comparison 

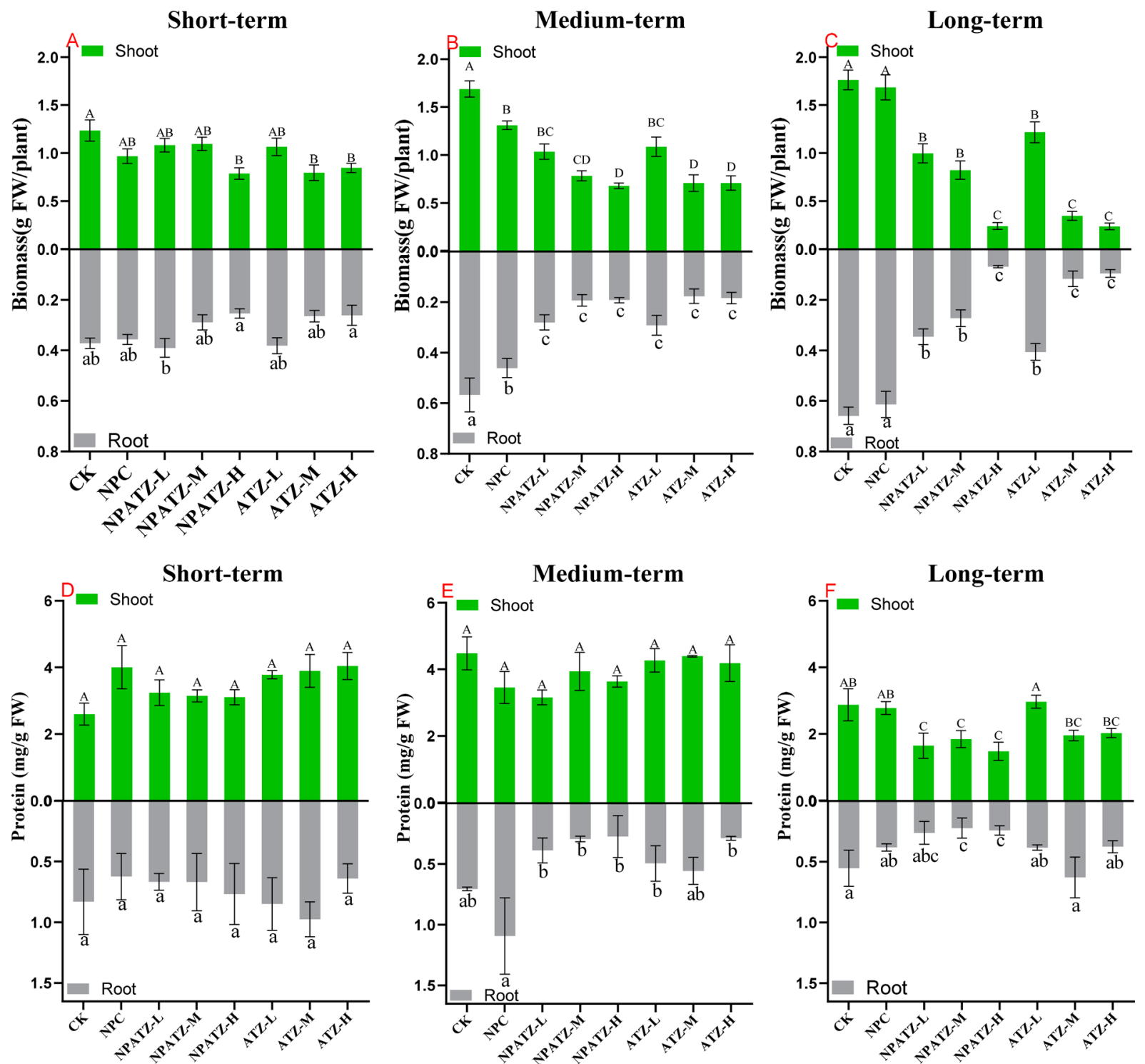

Figure 2. Fresh biomass (A, B, C) of lettuce (L. sativa) and protein content (D, E, F) in lettuce (Lactuca sativa) exposed to NPATZ and ATZ with concentrations ranging from low, medium, to high and different exposure durations (short-, medium- and long-term). Data are mean \pm SE $(n=3)$. The different letters indicate statistically significant differences between treatments within the same exposure duration by one-way ANOVA and Duncan's honestly significant difference tests at $\alpha<0.05$ (capital letters for shoot tissues and lower-caseletters for root tissues). CK: control check, control plants without exposure to chemicals. NPC: exposure to a polymeric carrier without the ATZ (control). NPATZ-L: exposure to a low concentration of NPATZ. NPATZ-M: exposure to a medium concentration of NPATZ. NPATZ-H: exposure to a high concentration of NPATZ. ATZ-L: exposure to a low concentration of ATZ. ATZ-M: exposure to a medium concentration of ATZ. ATZ-H: exposure to a high concentration of ATZ.

with the control. As exposure time increased to medium-term exposure, the biomass of roots and shoots decreased significantly for ATZ and NPATZ (Figure 2B). After longterm exposure, the biomass in the NPC and CK treatments increased compared with the short- and medium-exposure. On the other hand, the biomass of both shoot and root decreased dramatically as the exposure of ATZ and NPATZ concentration increased. The treatment of ATZ-H reduced the shoot and root biomass from 1.72 to $0.24 \mathrm{~g}$ and from 0.66 to $0.10 \mathrm{~g}$, respectively. Compared with the impact of ATZ, the treatment of NPATZ-H induced a similar reduction in shoot and root biomass, with $0.24 \mathrm{~g}$ of shoot and $0.07 \mathrm{~g}$ of root observed in the pots (Figure 2C). However, NPATZ-M induced a lower reduction in shoot and root biomass than ATZ-M after long- term exposure, which could be correlated with the slower release profile of the nanopesticide. ${ }^{13}$

3.2. Plant Protein Content analysis. The effects of ATZ and NPATZ on the plants protein content along with exposure time are given in Figure 2D-F. In short-term and mediumterm exposure, there was no significant impact of ATZ or NPATZ on the protein content (Figure 2D,E). After increasing the exposure duration to 6 weeks (long-term exposure), slight but not significant decreases in the protein content were observed in the plant roots for the treatments of ATZ-M and ATZ-H. However, NPATZ was found to significantly reduce the protein content in both root and shoot tissues, even at a low exposure concentration (Figure 2F). This could be explained by the correlation between the nutrients levels, for example, phosphor and nitrogen, in the exposed soil and 

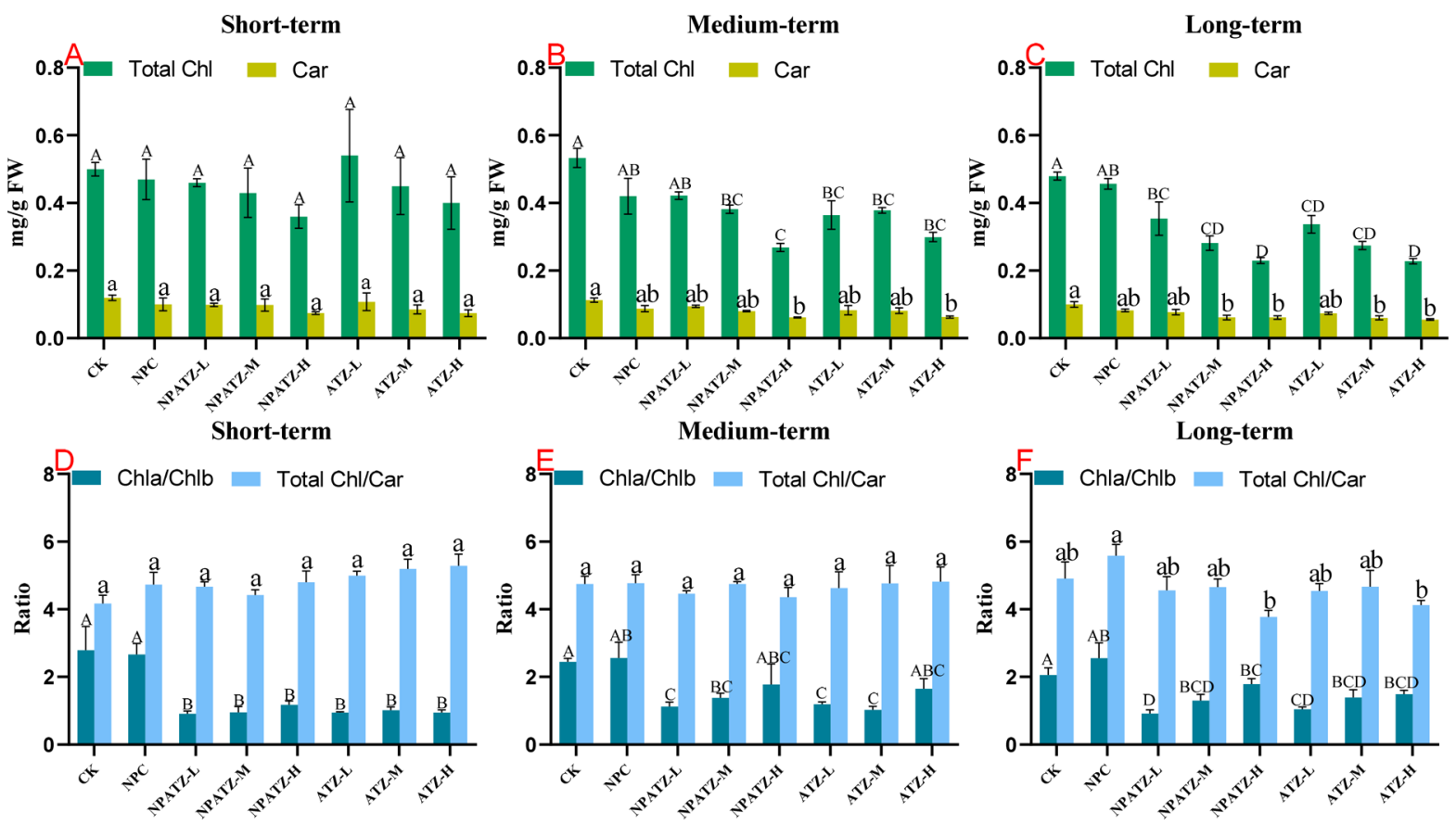

Figure 3. Total chlorophyll and carotenoid contents (A, B, C), and the ratio of Chla content to Chlb content and the ratio of total chlorophyll content to carotenoid content (D, E, F) in lettuce (L. sativa) exposed to NPATZ and ATZ with concentrations ranging from low, medium, to high and different exposure durations (short-, medium-, and long-term). Data are mean $\pm \operatorname{SE}(n=3)$. The different letters indicate statistically significant differences between treatments within the same exposure duration by one-way ANOVA and Duncan's honestly significant difference tests at $\alpha<0.05$ (capital letters for shoot tissues and lower-caseletters for root tissues). CK: control check, control plants without exposure to chemicals. NPC: exposure to a polymeric carrier without the ATZ (control). NPATZ-L: exposure to a low concentration of NPATZ. NPATZ-M: exposure to a medium concentration of NPATZ. NPATZ-H: exposure to a high concentration of NPATZ. ATZ-L: exposure to a low concentration of ATZ. ATZ-M: exposure to a medium concentration of ATZ. ATZ-H: exposure to a high concentration of ATZ.

proteins level in the plant, where a decrease in the level of nutrients is directly associated with a decrease of the level of proteins in plants because plants can use proteins as a source of nutrients. ${ }^{35}$ Phosphate solubilization and nitrogen fixation, which are mainly carried out naturally in soil by bacteria such as azotobacter and archaea, might be disrupted as a result of exposure to NPATZ leading to nutrients deficiency in plants. Our previous study showed that the microbiome as nontarget microorganisms could be influenced by NPATZ, ${ }^{18}$ thus, NPATZ indirectly could influence the level of protein by influencing the soil microbiome. Although we developed the NPATZ as particles that are not targeting lettuce, an indirect effect might be observed. It implies that the indirect influences of nanoparticles must be known to assist in the modification of NPATZ to provide safer particles.

3.3. Plant Photosynthetic Performance. The level of total chlorophyll and carotenoids in leaves were measured as the indicator of photosynthetic performance of the plants, and the effects of ATZ and NPATZ on the chlorophyll and carotenoids along with exposure time are shown in Figure 3. There were no statistically significant differences between the blank control and NPC in both total chlorophyll and carotenoids, regardless of the exposure duration. No significant difference was found among the treatments in short-term exposure (Figure 3A). In the medium-term exposure, a concentration-dependent inhibition effect on the content of total chlorophyll and carotenoids was observed in both ATZ and NPATZ treatments (Figure 3B). After long-term exposure, the decreases in chlorophyll and carotenoids content were enhanced in both ATZ and NPATZ treatments, where significant impacts on the chlorophyll and carotenoids were found in treatments of ATZ-M, ATZ-H, NPATZ-M, and NPATZ-H (Figure 3C). The chlorophyll content (based on fresh weight, FW) decreased from 0.480 (Control treatment) to $0.230 \mathrm{mg} / \mathrm{g} \mathrm{FW}$ (ATZ-H treatment) and $0.230 \mathrm{mg} / \mathrm{g} \mathrm{FW}$ (NPATZ-H treatment), respectively. The carotenoids content decreased from 0.100 (control treatment) to $0.055 \mathrm{mg} / \mathrm{g} \mathrm{FW}$ (ATZ-H treatment) and $0.061 \mathrm{mg} / \mathrm{g}$ FW (NPATZ-H treatment), respectively. This indicated that ATZ and NPATZ affected the photosynthetic performance of the plants, and the impacts were enhanced along with increasing exposure concentration and incubation time. We must emphasize that the designed NPATZ has a lifetime of $11.5 \mathrm{~h}$ in water and degrade over time when occurring in soil, where a high concentration of the NPATZ is presented as ATZ after 16 days. ${ }^{18}$ Thus, the observed effects after long-time exposure could result from the ATZ rather than NPATZ. In this study we applied the same quantity of the NPATZ and ATZ to compare the possible adverse effect. The advantage of NPATZ over ATZ, however, is that application of much lower concentration.

The ratios of chla/chlb and the total chlorophyll/ carotenoids in plants exposed to NPATZ and ATZ along with exposure time are provided in Figure 3D-F. No significant difference in the ratio of total chl/car was observed among the treatments in short-term and medium-term exposure (Figure 3D,E). After long-term exposure, although not significant, the ratio of total chl/car in NPATZ-H and ATZ-H treatments decreased by 23 and $16 \%$, respectively, as compared with control. Regarding the ratio of chla/chlb, significant decreases were observed for both NPATZ and ATZ treatments regardless of exposure time, but no significant 

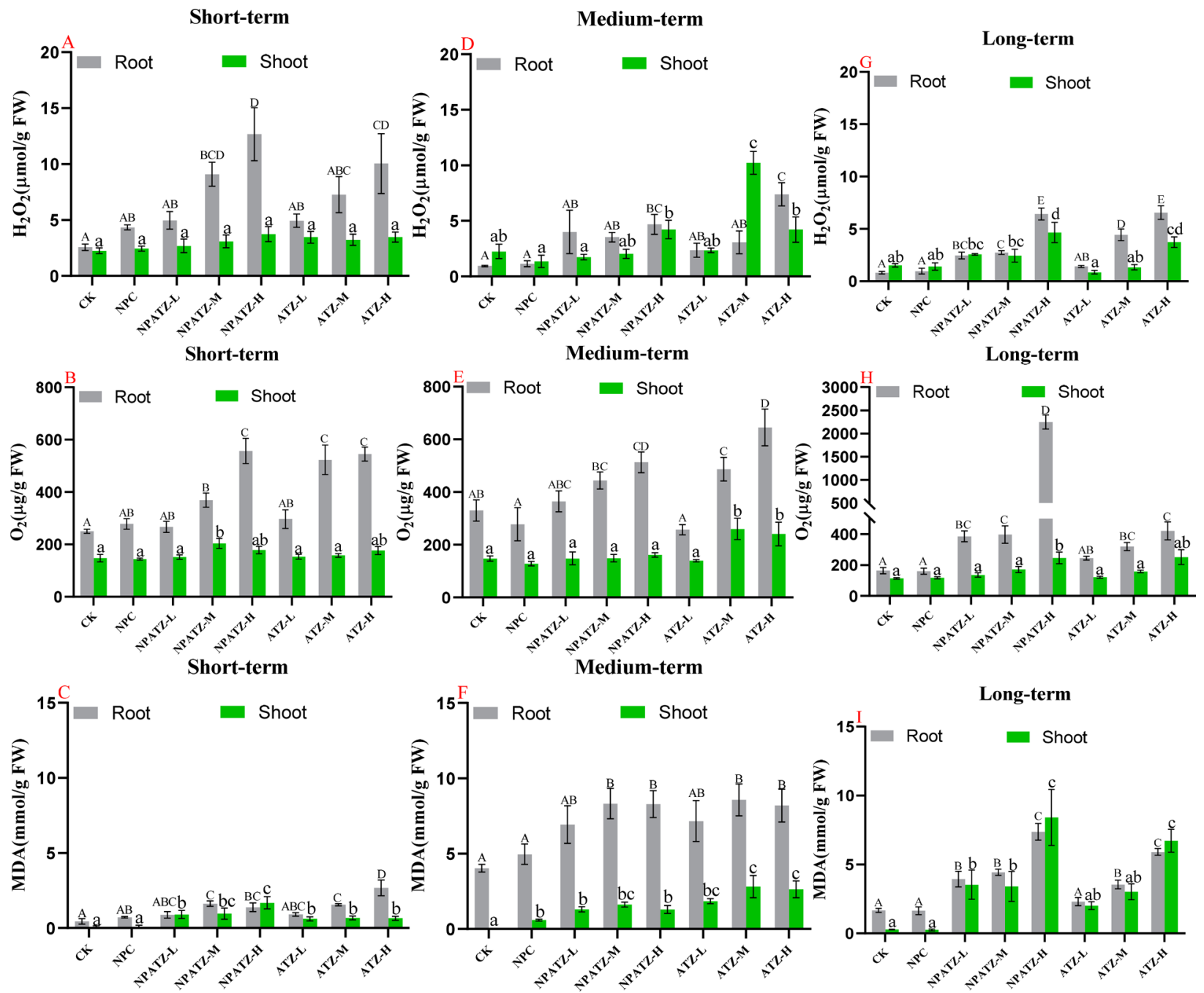

Figure 4. $\mathrm{H}_{2} \mathrm{O}_{2}, \mathrm{O}_{2}^{-}$, and MDA production in L. sativa exposed to NPATZ and ATZ with concentrations ranging from low, medium, to high and different exposure durations (short-, medium- and long-term). Data are mean \pm SE $(n=3)$. FW: fresh weight. The different letters indicate statistically significant differences between treatments within the same exposure duration by one-way ANOVA and Duncan's honestly significant difference tests at $\alpha<0.05$ (capital letters for shoot tissues and lower-caseletters for root tissues). CK: control check, control plants without exposure to chemicals. NPC: exposure to a polymeric carrier without the ATZ (control). NPATZ-L: exposure to a low concentration of NPATZ. NPATZ-M: exposure to a medium concentration of NPATZ. NPATZ-H: exposure to a high concentration of NPATZ. ATZ-L: exposure to a low concentration of ATZ. ATZ-M: exposure to a medium concentration of ATZ. ATZ-H: exposure to a high concentration of ATZ.

change was observed between NPATZ and ATZ at the same exposure concentration.

3.4. Accumulation of Reactive Oxygen Species (ROS) and MDA Production. The effects of ATZ and NPATZ on the plants ROS production were further investigated with a focus on $\mathrm{H}_{2} \mathrm{O}_{2}, \mathrm{O}_{2}^{-}$, and MDA production (Figure 4). In short-term exposure, both NPATZ and ATZ treatments significantly stimulated the $\mathrm{H}_{2} \mathrm{O}_{2}, \mathrm{O}_{2}{ }^{-}$, and MDA production in the roots. However, in plant shoots, significant stimulation induced by NPATZ and ATZ was only observed for MDA production compared to the control. In addition, the content of $\mathrm{H}_{2} \mathrm{O}_{2}, \mathrm{O}_{2}{ }^{-}$and MDA in plant root tissues were significantly higher than those in the shoot (Figure $4 \mathrm{~A}-\mathrm{C}$ ). In mediumterm exposure of ATZ and NPATZ, the stimulation of $\mathrm{H}_{2} \mathrm{O}_{2}$, $\mathrm{O}_{2}{ }^{-}$and MDA production in root were found to be concentration-dependent, with the production of $\mathrm{H}_{2} \mathrm{O}_{2}$ in ATZ treatment as the exception. In terms of $\mathrm{H}_{2} \mathrm{O}_{2}, \mathrm{O}_{2}{ }^{-}$and MDA production in shoot, stimulation was mainly observed in the treatments of NPATZ-H, ATZ-M, and ATZ-H (Figure
$4 \mathrm{D}-\mathrm{F}$ ). After long-term exposure of ATZ and NPATZ, the $\mathrm{H}_{2} \mathrm{O}_{2}, \mathrm{O}_{2}{ }^{-}$, and MDA production in both root and shoot were enhanced as compared to control (Figure 4G-I). Notably, in the treatment of NPATZ-H, the contents of $\mathrm{O}_{2}{ }^{-}$dramatically increased from 164 to $2250 \mu \mathrm{g} / \mathrm{g} \mathrm{FW}$ in root and from 114 to $246 \mu \mathrm{g} / \mathrm{g}$ FW in shoot, respectively (Figure $4 \mathrm{H}$ ). These results indicated that both ATZ and NPATZ stimulated the $\mathrm{H}_{2} \mathrm{O}_{2}$, $\mathrm{O}_{2}{ }^{-}$, and MDA production in plant root and shoot tissues, and $\mathrm{O}_{2}^{-}$production was largely enhanced in long-term exposure of NPATZ at high concentration.

3.5. Analysis of Stress-Related Enzyme Activity. The effects of ATZ and NPATZ on stress-related enzymes were investigated with the focus on SOD, APX, CAT, POD, GST, and PPO activities. The results are given in Figure 5 and the statistically significant differences for the tested enzymes between treatments are provided in SI Table S2. There were no statistically significant differences between the blank control and NPC regarding all the tested enzyme activities in both plant roots and shoots, regardless of the exposure duration. In 


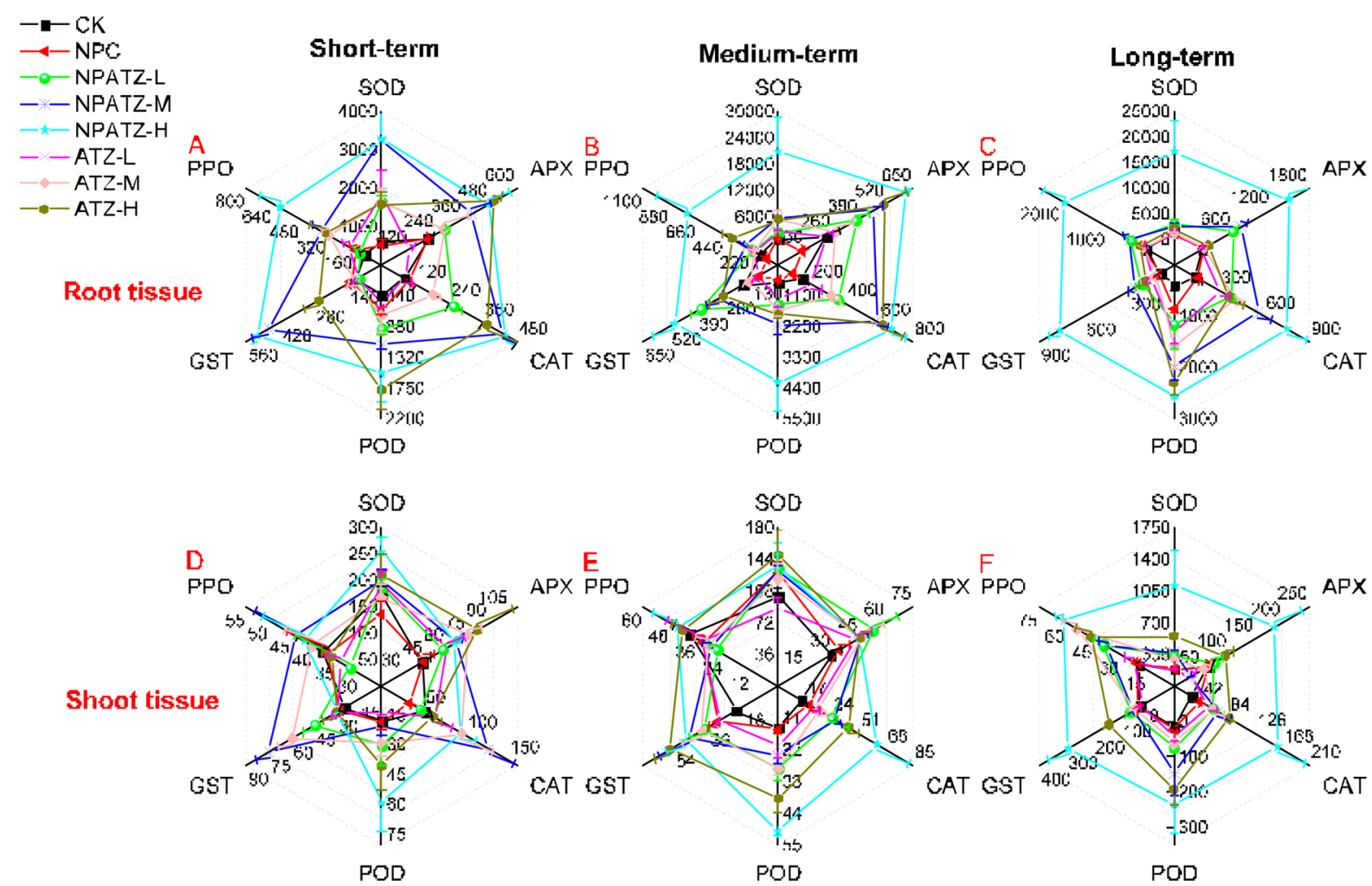

Figure 5. Antioxidant enzyme activities (SOD, APX, CAT, POD, GST, and PPO, Unit/mg protein/min) in L. sativa exposed to NPATZ and ATZ with concentrations ranging from low, medium, to high and different exposure durations (short-, medium- and long-term). Data are mean \pm SE ( $n$ = 3). CK: control check, control plants without exposure to chemicals. NPC: exposure to a polymeric carrier without the ATZ (control). NPATZL: exposure to a low concentration of NPATZ. NPATZ-M: exposure to a medium concentration of NPATZ. NPATZ-H: exposure to a high concentration of NPATZ. ATZ-L: exposure to a low concentration of ATZ. ATZ-M: exposure to a medium concentration of ATZ. ATZ-H: exposure to a high concentration of ATZ.

general, the effects of NPATZ and ATZ on the enzyme activities in plant roots were much higher than those in plant shoots. In short-term exposure, the enzyme activities of APX, CAT, POD, and PPO in the roots increased as the exposure concentration of NPATZ and ATZ increased (Figure 5A, SI Table S2). Compared with changes in roots, the enzymes activity in shoots were not significantly changed by the exposure to ATZ or NPATZ, with the POD activity in the NPATZ-H treatment and the GST activity in the treatments of NPATZ-M and ATZ-M as the exceptions (Figure 5D, SI Table S2). As incubation time increased to medium-term exposure, a clear concentration-dependent pattern of alterations of enzymes activity was observed between the plant roots and NPATZ exposure concentration except for GST activity (Figure 5B). However, there was no significant change in the tested enzyme activities in plant roots in all ATZ treatments as compared to control, except for the CAT activity in the ATZ$\mathrm{H}$ treatment (Figure 5B, SI Table S2). For plant shoots, statistically significant increases in CAT activity in NPATZ-H and POD activity in NPATZ-H, ATZ-M and ATZ-H were observed as compared to control (Figure 5E, SI Table S2). After long-term exposure, all tested enzyme activities in plants exposed to NPATZ were significantly higher than that in plants of the control regardless of considering root or shoot tissues (Figure 5C,F, SI Table S2). Compared with NPATZ, the impacts of ATZ on the enzyme activity of plant roots appeared lower, with only CAT and POD activity significantly promoted (Figure 5C, SI Table S2). Therefore, these results revealed that the responses of the tested enzyme activity were more sensitive in plants roots than in the shoots. NPATZ triggered a stronger stimulation of stress-related enzyme activity than ATZ after long-term exposure. It implies that by using nanoformulation of ATZ, the time of effect can be increased, which is a very important outcome to show how nanoformulation may assist in designing time-controlled pesticides.

3.6. Analysis of Macro-and Micronutrients in Lettuce Plants. The concentrations of macro-and micronutrients in roots and shoots of lettuce plants exposed to different ATZ and NPATZ treatments over time are provided in Table 1. There were no statistically significant differences between the blank control and the NPC regarding all elements tested in both plant roots and shoots regardless of the exposure duration, except for the $\mathrm{K}$ concentration in roots in shortterm exposure. This suggests that the polymeric nanocapsules had no effect on the nutrient uptake in lettuce. In short-term exposure, both ATZ and NPATZ exposure significantly increased the concentration of $\mathrm{K}, \mathrm{Mg}, \mathrm{B}, \mathrm{Fe}$ and significantly decreased the concentration of $\mathrm{Cu}$ in plant roots. For $\mathrm{Zn}$ and $\mathrm{Mn}$ in plant roots upon short-term exposure, there were no differences among all treatments. For the plant shoots, significant increases in $\mathrm{Mg}, \mathrm{B}$, and $\mathrm{Zn}$ concentrations were only observed in the NPATZ treatments. Significant changes of the concentration of nutrients in plants of the NPATZ treatments relative to the corresponding ATZ treatments were observed for $\mathrm{K}$ (increase), $\mathrm{Mg}$ and $\mathrm{Fe}$ (decrease) in plant roots and $\mathrm{B}$ (increase) in plant shoots. As exposure time increased to the medium-term exposure, an increase of the $\mathrm{K}$ concentration in plant roots and shoots was observed in both ATZ and 


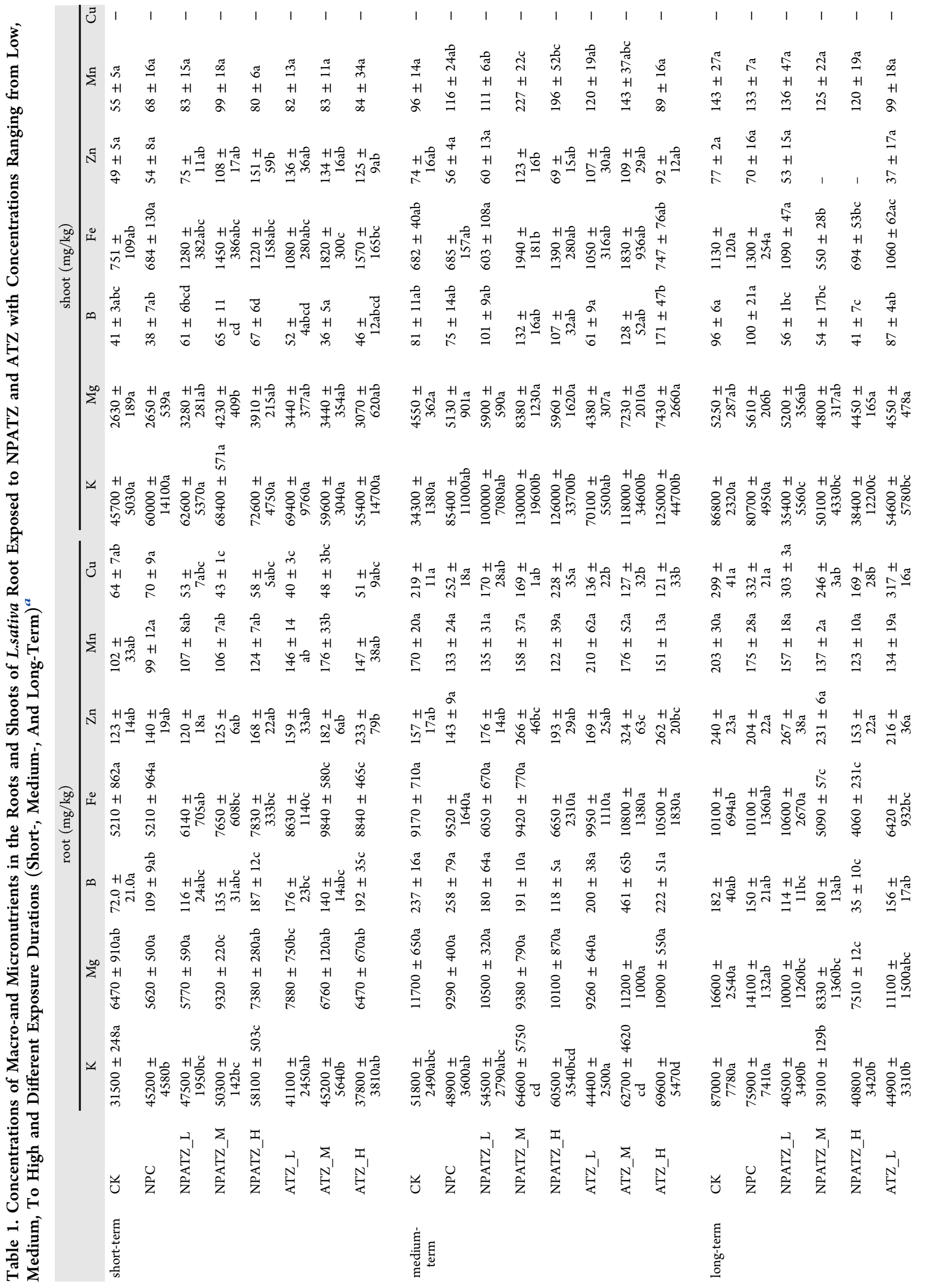


NPATZ treatments. Decreases in the $\mathrm{Cu}$ concentration in plant roots were only observed in ATZ treatments. As compared to ATZ treatments, a lower concentration of B and a higher concentration of $\mathrm{Cu}$ were observed in plant roots of NPATZ treatments, while a higher concentration of Mn was observed in plant shoots of NPATZ treatment. After long-term exposure to NPATZ and ATZ, the concentrations of $\mathrm{K}, \mathrm{Mg}, \mathrm{B}$, $\mathrm{Fe}$, and $\mathrm{Cu}$ in plant roots were found to be significantly decreased, especially in the treatments of ATZ-H and NPATZ$\mathrm{H}$. Decreases in $\mathrm{K}$ and $\mathrm{B}$ concentrations were also observed in plants shoots exposed to ATZ and NPATZ. A significant decrease of the concentration of $\mathrm{Zn}$ in plant roots and the $\mathrm{Fe}$ concentration in plant shoots was observed for NPATZ treatments as compared to the corresponding treatments of ATZ.

Moreover, the translocation factors (TFs) of the tested nutrient elements were given in SI Table S3. Only the TFs of K in the treatments were found to be $>1$ regardless of the exposure concentration and time, suggesting that most of the $\mathrm{K}$ was translocated from roots to shoots. As compared to control, a clear significant increase of the TFs was only observed for $\mathrm{K}$ in NPATZ and ATZ treatments upon medium-term exposure and for $\mathrm{Mn}$ in NPATZ treatments upon medium-term exposure. In addition, a clear significant decrease of TFs was only observed for Zn in NPATZ and ATZ treatments upon long-term exposure in comparison with control, especially in the treatments of NPATZ-M, NPATZ-H, and ATZ-H, suggesting impacts on the translocation of $\mathrm{Zn}$ from plant roots to shoots. These results indicated that exposure duration significantly differentiated the impacts of NPATZ and ATZ on nutrient displacement in plants, and long-term exposure of the plants to NPATZ and ATZ induced different effects on the uptake of nutrients in lettuce roots and shoots.

\section{DISCUSSION}

In this study, a nanopesticide containing ATZ as the active ingredient and the biodegradable poly- $\varepsilon$-caprolactone (PCL) polymer as a carrier was synthesized, and the impacts of the nanopesticide and its nonencapsulated form were compared during short- to long-term exposure on the growth of lettuce. Although plant growth was not a sensitive end point during the short-term exposure, reductions in biomass were enhanced as the ATZ and NPATZ exposure concentration, and the duration increased. A previous study observed that the shortterm exposure of nanocapsulated atrazine and noncapsulate atrazine induced a significant decrease in the dry biomass of soybean, whereas the inhibition was not enhanced after longterm exposure. ${ }^{5}$ Moreover, it was also reported that NPATZ did not induce harmful impacts on maize plants but did have negative effects on mustard plants. ${ }^{31,15}$ These results indicate that the effect of ATZ and NPATZ are species dependent. Further studies focusing on understanding species-specificity and sensitivity of nanopesticides are needed, as these studies can contribute to promoting the nanopesticides safety and efficiency in agricultural applications.

It has been well documented that the mechanism of action of atrazine is to inhibit the photosynthetic processes of the plants, resulting in leaf chlorosis and necrosis, and even plant death. Specifically, atrazine interrupts the photosystem II (PSII) by blocking electron acceptor proteins and inhibiting the electron transport chain in the chloroplast. ${ }^{22}$ In the present study, obvious toxic symptoms of leaf wilt, yellowing, and necrosis as well as significant decreases in chlorophyll contents 
were observed after long-term ATZ and NPATZ exposure. It is reasonable to infer that chlorophyll synthesis might be affected after long-term exposure to high concentrations of NPATZ and ATZ. In addition, the ratio of the chla to chlb and the ratio of total chlorophyll to carotenoids are the fundamental parameters for photosynthetic activity, and their deviations are often used as an indicator of stress in plants. In this study, the significantly decreased ratio of chla/chlb in lettuces suggests the strong inhibition of photosynthetic synthesis in response to NPATZ and ATZ addition. In accordance with our study, several recent studies also showed that nanoatrazine results in a greater inhibition of photosynthesis in plants, including Amaranthus viridis, ${ }^{36}$ Bidens Pilosa, ${ }^{36}$ Digitaria insularis, ${ }^{37}$ Zea mays L., ${ }^{31}$ and Brassica juncea. ${ }^{15}$

The inhibition of photosynthesis in plants by atrazine was accompanied by the generation of a large amount of ROS. ${ }^{23}$ The production of excess reactive oxygen species in plants causes lipid peroxidation and damaged cell membrane permeability, eventually resulting in death plants. ${ }^{38}$ Our results revealed that a general concentration-dependent increase of ROS production (i.e., $\mathrm{O}_{2}^{-}$and $\mathrm{H}_{2} \mathrm{O}_{2}$ contents) in plants was observed in both NPATZ and ATZ treatments. Moreover, ROS production and MDA content in roots were observed to be higher than in the shoots, and more $\mathrm{O}_{2}{ }^{-}$production in roots was found in the long term exposure to the NPATZ-H compared with the ATZ-H treatment. This indicates that roots exhibited a higher susceptibility to long-term NPATZ exposure than shoots. Considering that the nanoformulation is designed to enhance the efficiency of the active ingredient, ${ }^{27}$ the released atrazine could be initially absorbed on the root surface, thus stimulating the ROS production in roots. ${ }^{15,39}$

It is well-known that excessive ROS production in plants makes plants suffer from oxidative stress and even leads to irreversible damage to proteins, lipids, chloroplastic pigments, and DNA, thereby affecting normal cellular functioning. ${ }^{40}$ To defend/counteract the excessive ROS production and maintain the redox status, plants activate their antioxidant defense systems for self-protection. The activities antioxidant enzymatic in plants, for example, Triticum aestivum L., ${ }^{38}$ Pisum sativum L., ${ }^{41}$ and Pennisetum americanum (L.) K. Schum ${ }^{25}$ have been found to depend on enzyme type and plant organ. Our findings revealed that ATZ and NPATZ affected plants' enzyme activity over time, depending on the enzyme types and plant organs. The activities of all the tested enzymes in plant roots were much higher compared to the activities in plant shoots. This further indicated that roots suffered more severe oxidative stress and exhibited more pronounced ROS scavenging ability than the shoots. Moreover, we observed that the stress-related enzyme activity (i.e., SOD, APX, GST, and $\mathrm{PPO}$ ) in plants roots increased in the short term but decreased after long-term ATZ exposure. It has been reported that as long as the stresses do not exceed the tolerance threshold of plants, the antioxidant defense system in plants can adapt to the oxidative stress and recover to some extent ${ }^{42}$ as the ATZ exposure time increases. However, the enzyme activity of SOD, APX, CAT, GST, and PPO in NPATZ treatment increased over time and these activities were stronger as compared to ATZ treatment. The enzymes of SOD, APX, CAT, and POD have been widely reported as the first line of defense enzymes to eliminate the overproduction of ROS in plants. ${ }^{17,40,43}$ The SOD can convert the superoxide radical to $\mathrm{H}_{2} \mathrm{O}_{2}$ which can be further decomposed by the CAT, APX, and POD into $\mathrm{H}_{2} \mathrm{O} .{ }^{17,29}$ In addition, the enzyme of GST catalyzes the conjugation of the glutathione to xenobiotic substrates via sulfhydryl groups, which then subsequently lowers contaminant toxicity to the plant. ${ }^{29}$ The antioxidant enzyme PPO, which converts phenols into quinones, is associated with ROS removal and metal detoxification. ${ }^{29}$ This further indicates that the nanoformulation enhanced the efficiency of the active ingredient, ${ }^{15,39}$ thus long-term exposure of NPATZ induced more severe oxidative damage in plants.

In this study, the impacts of ATZ and NPATZ on plants' elemental uptake were found to depend on the nutrient type, plant organ, exposure concentration, and time. The displacement of nutrients in plant roots was observed to be higher in the shoots in both ATZ and NPATZ treatments. Root exposure to contaminants in the rhizosphere could greatly change the composition and content of root exudates, which could in turn affect the uptake of nutrients in plants. ${ }^{44}$ In both shoots and roots, we observed that the $\mathrm{K}$ content increased transiently but decreased after long-term ATZ and NPATZ exposure. The $\mathrm{K}$ is known to be involved in detoxifying oxygen radicals and assist in maintaining cell membrane stability. ${ }^{45,46}$ The up-regulation of $\mathrm{K}$ in plants might be an action of lettuces to defend itself against ROS-induced stress due to the NPATZ and ATZ exposure. This can affect the response of plant roots, as attachment of either NPATZ or ATZ directly or indirectly blocks the channels of aquaporin proteins and metal transport, and inhibits the uptake of mineral nutrients in plants. ${ }^{47,48} \mathrm{~A}$ similar time-dependent trend of the concentration of $\mathrm{K}$ was also observed for $\mathrm{Mg}, \mathrm{B}$, and $\mathrm{Fe}$ in plants roots exposed to NPATZ and ATZ. This highlights that exposure time is important in determining the effects of NPATZ and ATZ on nutrient displacement in plants, and could be modified during modification of the nanoformulations. In addition, the contents of $\mathrm{Cu}$ and $\mathrm{Fe}$ in plant roots decreased after long-term exposure to both NPATZ and ATZ. This finding is consistent with the observations of decreased total chlorophyll as well as leaf wilt, yellowing, and necrosis. Both $\mathrm{Cu}$ and $\mathrm{Fe}$ are involved in plant leaf photosynthesis directly, and their deficiency can lead to the impairment of electron transfer, leaf necrosis, and stunted growth of plants. ${ }^{47,49,50}$ Notably, a significant decrease of the concentration of Fe in plant shoots was only observed in longterm NPATZ exposure, indicating the adverse effects of NPATZ on the mineral nutrient uptake.

Comparing the impacts of ATZ and NPATZ on plants growth, photosynthetic performance, ROS production, stressrelated enzyme activity, and elemental uptake, our results demonstrated that NPATZ induced different adverse effects on the lettuce plant compared to the conventional form when evaluated in the same concentration, which can be explained by the mode of action of the formulation with the plants and soil. For example, the solubility and stability of the active ingredient atrazine in the nanoformulation was enhanced as compared to the conventionally administered atrazine. The polymeric chains of the carriers will rearrange the release of atrazine that is encapsulated in a nanosized polymeric shell into soil by a combination of solvent diffusion and polymeric relaxation which possesses and enhances the targeted delivery of the active ingredient to plants. Importantly, one of the key purposes of a nanoformulation is to effectively control the target weed species with lower amounts of the required active ingredient. For instance, Pereira et al. concluded that NPATZ improved its pre-emergence herbicidal activity against the target. ${ }^{5}$ Moreover, Oliveira et al. demonstrated that the postemergence herbicidal activity of NPATZ was 10 times 
more effective than ATZ and the nanoformulation lowered the required dosages of atrazine. ${ }^{15}$ Recently, Takeshita et al. showed that NPATZ provided 2-fold higher weed control in the field compared to commercial atrazine. ${ }^{51}$ In this study, if we compared the impact of the NPATZ (the same used in Oliveira et $\mathrm{al}^{32}$ ) on lettuce plants at the lowest concentration (NPATZ-L) with the conventional form in its highest concentration (ATZ-H), a clear reduction in their toxicity effects was observed since the formulation will be diluted 10 times. Therefore, herbicidal efficiency should also be linked to study the impact of the nanopesticides, and not just compare nanopesticides with its conventional form at the same concentration. Moreover, the study of long-term impacts of nanopesticides on the nontarget species as well as understanding the mechanism of action is essential to follow the environmental risk assessment of nanopesticides. ${ }^{10}$ For instance, our previous study also found that NPATZ improved the biological activity of atrazine against the nontarget rhizosphere bacterial community. ${ }^{18}$ One of the possible reasons for the enhanced activity of NPATZ is attributed to the higher mobility and bioavailability in the soil matrix, which in turn improves their delivery efficiency to target and nontarget organisms. ${ }^{15,18,39}$

In summary, our results indicate that the effects of atrazine (ATZ) and the nanoformulation of atrazine (NPATZ) are different. The nanoformulation inhibited the growth of lettuce at the same extent as atrazine does in short-term exposure. However, long-term exposure to high concentrations of NPATZ induced stronger negative effects on the end points selected being protein content, ROS productions, and alteration of enzyme activities, as compared to nonencapsulated form when applied in the same concentration. Additionally, NPATZ and ATZ both induced displacement of nutrients, for example, $\mathrm{K}, \mathrm{Fe}$, and $\mathrm{Cu}$ for plant growth, but the mode of action of NPATZ and ATZ differed depending on the nutrient element considered, plant organ, and exposure time. As the long-term effects of nanoformulation has been confirmed, this gives the opportunity to decrease the amount of required pesticides by increasing the time of effect or even controlling the time of effect using nanoparticles modification. Future work regarding the agricultural application should explore the optimal additional dose of nanopesticide toward achieving high efficiency as well as low environmental impacts, which is an important step to achieve its "green and clean" claims.

\section{ASSOCIATED CONTENT}

\section{SI Supporting Information}

The Supporting Information is available free of charge at https://pubs.acs.org/doi/10.1021/acs.jafc.1c01382.

Additional information regarding preparation and SEM picture of Atrazine (ATZ) loaded poly- $\epsilon$-caprolactone nanocapsules (NPATZ), kinetic plots assessing the release profiles of the herbicide ATZ from the NPATZs in water and soil, physicochemical properties of the soil and culture media for the plants were provided. Methods for enzyme extraction, analysis of superoxide dismutase (SOD), peroxidase (POD), catalase (CAT), ascorbate peroxidase (APX), polyphenol oxidase (PPO) and glutathione s-transferase (GST) were also reported (PDF)

\section{AUTHOR INFORMATION}

\section{Corresponding Authors}

Yujia Zhai - Leiden University, Institute of Environmental Sciences (CML), 2300 RA Leiden, The Netherlands; ○ orcid.org/0000-0002-7412-6111; Email: y.zhai@ tudelft.nl

Willie J. G. M. Peijnenburg - Leiden University, Institute of Environmental Sciences (CML), 2300 RA Leiden, The Netherlands; National Institute of Public Health and the Environment (RIVM), Bilthoven 3720 BA, The Netherlands; Email: Peijnenburg@cml.leidenuniv.nl

\section{Authors}

Juan Wu - Leiden University, Institute of Environmental Sciences (CML), 2300 RA Leiden, The Netherlands; (1) orcid.org/0000-0003-2694-1127

Fazel Abdolahpur Monikh - Leiden University, Institute of Environmental Sciences (CML), 2300 RA Leiden, The Netherlands

Daniel Arenas-Lago - University of Vigo, Department of Plant Biology and Soil Science, As Lagoas, 32004 Ourense, Spain

Renato Grillo - Department of Physics and Chemistry, School of Engineering, São Paulo State University (UNESP), 15385000 Ilha Solteira, SP, Brazil

Martina G. Vijver - Leiden University, Institute of Environmental Sciences (CML), 2300 RA Leiden, The Netherlands

Complete contact information is available at: https://pubs.acs.org/10.1021/acs.jafc.1c01382

\section{Notes}

The authors declare no competing financial interest.

\section{ACKNOWLEDGMENTS}

We thank Guiyin Wang (Leiden University) for the help with soil collection and preparation. The China Scholarship Council (CSC) is gratefully acknowledged for its financial support to Juan Wu (201706750014). D.A.-L. thanks to Xunta de Galicia and the Universidade de Vigo for his postdoc contract (ED481D 2019/007). R.G. thanks to National Council for Scientific and Technological Development, CNPq (grant no. 427498/2018-0), São Paulo Research Foundation, FAPESP (grant no. \#2017/21004-5), and CAPES - Finance Code 001.

\section{REFERENCES}

(1) Schnoor, B.; Elhendawy, A.; Joseph, S.; Putman, M.; ChacónCerdas, R.; Flores-Mora, D.; Bravo-Moraga, F.; Gonzalez-Nilo, F.; Salvador-Morales, C. Engineering Atrazine Loaded Poly (Lactic- CoGlycolic Acid) Nanoparticles to Ameliorate Environmental Challenges. J. Agric. Food Chem. 2018, 66 (30), 7889-7898.

(2) Ehrsam, M.; Knutie, S. A.; Rohr, J. R. The Herbicide Atrazine Induces Hyperactivity and Compromises Tadpole Detection of Predator Chemical Cues. Environ. Toxicol. Chem. 2016, 35 (9), 2239-2244.

(3) Sass, J. B.; Colangelo, A. European Union Bans Atrazine, While the United States Negotiates Continued Use. International Journal of Occupational and Environmental Health; Hamilton Hardy Publishing Inc, 2006; pp 260-267. DOI: 10.1179/oeh.2006.12.3.260.

(4) USDA. United States Department of Agriculture, World Agricultural Production. Circular Series WAP 3-19; 2019.

(5) Preisler, A. C.; Pereira, A. E.; Campos, E. V.; Dalazen, G.; Fraceto, L. F.; Oliveira, H. C. Atrazine Nanoencapsulation Improves Pre-emergence Herbicidal Activity against Bidens Pilosa without 
Enhancing Long-term Residual Effect on Glycine Max. Pest Manage. Sci. 2020, 76 (1), 141-149.

(6) Market Research Future. Atrazine Market by Type, Size, Share and Global Forecast - 2024 I MRFR; 2020. https://www. marketresearchfuture.com/reports/atrazine-market-7128.

(7) Liu, Y.; Fan, X.; Zhang, T.; He, W.; Song, F. Effects of the LongTerm Application of Atrazine on Soil Enzyme Activity and Bacterial Community Structure in Farmlands in China. Environ. Pollut. 2020, 262, 114264.

(8) Walker, G. W.; Kookana, R. S.; Smith, N. E.; Kah, M.; Doolette, C. L.; Reeves, P. T.; Lovell, W.; Anderson, D. J.; Turney, T. W.; Navarro, D. A. Ecological Risk Assessment of Nano-Enabled Pesticides: A Perspective on Problem Formulation. J. Agric. Food Chem. 2018, 66 (26), 6480-6486.

(9) Grillo, R.; Mattos, B. D.; Antunes, D. R.; Forini, M. M. L.; Monikh, F. A.; Rojas, O. J. Foliage Adhesion and Interactions with Particulate Delivery Systems for Plant Nanobionics and Intelligent Agriculture. Nano Today 2021, 37, 101078.

(10) Grillo, R.; Fraceto, L. F.; Amorim, M. J. B.; Scott-Fordsmand, J. J.; Schoonjans, R.; Chaudhry, Q. Ecotoxicological and Regulatory Aspects of Environmental Sustainability of Nanopesticides. J. Hazard. Mater. 2021, 404, 124148.

(11) Castro, M. J. L.; Ojeda, C.; Cirelli, A. F. Advances in Surfactants for Agrochemicals. Environ. Chem. Lett. 2014, 12, 85-95. (12) Avellan, A.; Yun, J.; Zhang, Y.; Spielman-Sun, E.; Unrine, J. M.; Thieme, J.; Li, J.; Lombi, E.; Bland, G.; Lowry, G. V. Nanoparticle Size and Coating Chemistry Control Foliar Uptake Pathways, Translocation, and Leaf-to-Rhizosphere Transport in Wheat. ACS Nano 2019, 13 (5), 5291-5305.

(13) Grillo, R.; dos Santos, N. Z. P.; Maruyama, C. R.; Rosa, A. H.; de Lima, R.; Fraceto, L. F. Poly(E\{open\}-Caprolactone)Nanocapsules as Carrier Systems for Herbicides: Physico-Chemical Characterization and Genotoxicity Evaluation. J. Hazard. Mater. 2012, 231-232, 1-9.

(14) Gomes, S. I. L.; Scott-Fordsmand, J. J.; Campos, E. V. R.; Grillo, R.; Fraceto, L. F.; Amorim, M. J. B. On the Safety of Nanoformulations to Non-Target Soil Invertebrates-an Atrazine Case Study. Environ. Sci.: Nano 2019, 6 (6), 1950-1958.

(15) Oliveira, H. C.; Stolf-Moreira, R.; Martinez, C. B. R.; Grillo, R.; De Jesus, M. B.; Fraceto, L. F. Nanoencapsulation Enhances the PostEmergence Herbicidal Activity of Atrazine against Mustard Plants. PLoS One 2015, 10 (7), No. e0132971.

(16) Nuruzzaman, M.; Rahman, M. M.; Liu, Y.; Naidu, R. Nanoencapsulation, Nano-Guard for Pesticides: A New Window for Safe Application. J. Agric. Food Chem. 2016, 64 (7), 1447-1483.

(17) Andrade, L. L. de; do Espirito Santo Pereira, A.; Fernandes Fraceto, L.; Bueno dos Reis Martinez, C. Can Atrazine Loaded Nanocapsules Reduce the Toxic Effects of This Herbicide on the Fish Prochilodus Lineatus? A Multibiomarker Approach. Sci. Total Environ. 2019, 663, 548-559.

(18) Zhai, Y.; Abdolahpur Monikh, F.; Wu, J.; Grillo, R.; ArenasLago, D.; Darbha, G. K.; Vijver, M. G.; Peijnenburg, W. J. G. M. Interaction between a Nano-Formulation of Atrazine and Rhizosphere Bacterial Communities: Atrazine Degradation and Bacterial Community Alterations. Environ. Sci.: Nano 2020, 7 (11), 3372-3384.

(19) Kah, M.; Singh Kookana, R.; Gogos, A.; Daniel Bucheli, T. A Critical Evaluation of Nanopesticides and Nanofertilizers against Their Conventional Analogues. Nat. Nanotechnol. 201813677.

(20) Pascoli, M.; Lopes-Oliveira, P. J.; Fraceto, L. F.; Seabra, A. B.; Oliveira, H. C. State of the Art of Polymeric Nanoparticles as Carrier Systems with Agricultural Applications: A Minireview. Energy, Ecol. Environ. 2018, 3 (3), 137-148.

(21) Dan Hess, F. Light-Dependent Herbicides: An Overview. Weed Sci. 2000, 48 (2), 160-170.

(22) Fan, X.; Chang, W.; Feng, F.; Song, F. Responses of Photosynthesis-Related Parameters and Chloroplast Ultrastructure to Atrazine in Alfalfa (Medicago Sativa L.) Inoculated with Arbuscular Mycorrhizal Fungi. Ecotoxicol. Environ. Saf. 2018, 166, 102-108.

(23) Ramel, F.; Sulmon, C.; Bogard, M.; Couée, I.; Gouesbet, G. Differential Patterns of Reactive Oxygen Species and Antioxidative
Mechanisms during Atrazine Injury and Sucrose-Induced Tolerance in Arabidopsis Thaliana Plantlets. BMC Plant Biol. 2009, 9, 28.

(24) Zhang, Y.; Meng, D.; Wang, Z.; Guo, H.; Wang, Y.; Wang, X.; Dong, $\mathrm{X}$. Oxidative Stress Response in Atrazine-Degrading Bacteria Exposed to Atrazine. J. Hazard. Mater. 2012, 229-230, 434-438.

(25) Jiang, Z.; Ma, B.; Erinle, K. O.; Cao, B.; Liu, X.; Ye, S.; Zhang, Y. Enzymatic Antioxidant Defense in Resistant Plant: Pennisetum Americanum (L.) K. Schum during Long-Term Atrazine Exposure. Pestic. Biochem. Physiol. 2016, 133, 59-66.

(26) Ghosh, I.; Mukherjee, A.; Mukherjee, A. In Planta Genotoxicity of NZVI: Influence of Colloidal Stability on Uptake, DNA Damage, Oxidative Stress and Cell Death. Mutagenesis 2017, 32 (3), 371-387.

(27) Pereira, A. E. S.; Grillo, R.; Mello, N. F. S.; Rosa, A. H.; Fraceto, L. F. Application of Poly(Epsilon-Caprolactone) Nanoparticles Containing Atrazine Herbicide as an Alternative Technique to Control Weeds and Reduce Damage to the Environment. J. Hazard. Mater. 2014, 268, 207-215.

(28) Grillo, R.; Forini, M. M. L.; Antunes, D. R.; Cavalcante, L. A. F.; Pontes, M. S.; Biscalchim, E. R.; Sanches, A. O.; Santiago, E. F.; Fraceto, L. F. Fabrication and Characterization of a Novel Herbicide Delivery System with Magnetic Collectability and Its Phytotoxic Effect on Photosystem II of Aquatic Macrophyte. J. Agric. Food Chem. 2020, 68 (40), 11105-11113.

(29) Ma, C.; Liu, H.; Guo, H.; Musante, C.; Coskun, S. H.; Nelson, B. C.; White, J. C.; Xing, B.; Dhankher, O. P. Defense Mechanisms and Nutrient Displacement in: Arabidopsis Thaliana upon Exposure to $\mathrm{CeO} 2$ and In2O3 Nanoparticles. Environ. Sci.: Nano 2016, 3 (6), $1369-1379$.

(30) Hoagland, D. R.; Arnon, D. I. The Water-Culture Method for Growing Plants without Soil: University of California. Circular. Calif. Agric. Exp. Stn., 2nd ed., 1950, 347.

(31) Oliveira, H. C.; Stolf-Moreira, R.; Martinez, C. B. R.; Sousa, G. F. M.; Grillo, R.; de Jesus, M. B.; Fraceto, L. F. Evaluation of the Side Effects of Poly(Epsilon-Caprolactone) Nanocapsules Containing Atrazine toward Maize Plants. Front. Chem. 2015, 3, 61.

(32) Lichtenthaler, H. K. Chlorophylls and Carotenoids: Pigments of Photosynthetic Biomembranes. Methods Enzymol. 1987, 148 (C), 350-382.

(33) Wang, A.; Luo, G. Quanititative Relation between the Reaction of Hydroxylamine and Superoxide Anion Radicals in Plants. Plant Physiol Commun. 1990, 6, 55-57. (in Chinese)

(34) Mosa, K. A.; El-Naggar, M.; Ramamoorthy, K.; Alawadhi, H.; Elnaggar, A.; Wartanian, S.; Ibrahim, E.; Hani, H. Copper Nanoparticles Induced Genotoxicty, Oxidative Stress, and Changes in Superoxide Dismutase (SOD) Gene Expression in Cucumber (Cucumis Sativus) Plants. Front. Plant Sci. 2018, 9, 872.

(35) Paungfoo-Lonhienne, C.; Lonhienne, T. G. A.; Rentsch, D.; Robinson, N.; Christie, M.; Webb, R. I.; Gamage, H. K.; Carroll, B. J.; Schenk, P. M.; Schmidt, S. Plants Can Use Protein as a Nitrogen Source without Assistance from Other Organisms. Proc. Natl. Acad. Sci. U. S. A. 2008, 105 (11), 4524-4529.

(36) Sousa, G. F. M.; Gomes, D. G.; Campos, E. V. R.; Oliveira, J. L.; Fraceto, L. F.; Stolf-Moreira, R.; Oliveira, H. C. Post-Emergence Herbicidal Activity of Nanoatrazine Against Susceptible Weeds. Front. Environ. Sci. 2018, 6 (MAR), 12.

(37) Sousa, B. T.; Santo Pereira, A. do E.; Fraceto, L. F.; de Oliveira, H. C.; Dalazen, G. Effectiveness of Nanoatrazine in Post-Emergent Control of the Tolerant Weed Digitaria Insularis. J. Plant Prot. Res. 2020, 60 (2), 185-192.

(38) Silva, S.; Ferreira de Oliveira, J. M. P.; Dias, M. C.; Silva, A. M. S.; Santos, C. Antioxidant Mechanisms to Counteract TiO2Nanoparticles Toxicity in Wheat Leaves and Roots Are Organ Dependent. J. Hazard. Mater. 2019, 380, 120889.

(39) Sun, Y.; Liang, J.; Tang, L.; Li, H.; Zhu, Y.; Jiang, D.; Song, B.; Chen, M.; Zeng, G. Nano-Pesticides: A Great Challenge for Biodiversity? Nano Today 2019, 28, 100757.

(40) Das, K.; Roychoudhury, A. Reactive Oxygen Species (ROS) and Response of Antioxidants as ROS-Scavengers during Environmental Stress in Plants. Front. Environ. Sci. 2014, 2, 53. 
(41) García-Gómez, C.; Obrador, A.; González, D.; Babín, M.; Fernández, M. D. Comparative Study of the Phytotoxicity of $\mathrm{ZnO}$ Nanoparticles and $\mathrm{Zn}$ Accumulation in Nine Crops Grown in a Calcareous Soil and an Acidic Soil. Sci. Total Environ. 2018, 644, 770-780.

(42) Ahammed, G. J.; Wang, M. M.; Zhou, Y. H.; Xia, X. J.; Mao, W. H.; Shi, K.; Yu, J. Q. The Growth, Photosynthesis and Antioxidant Defense Responses of Five Vegetable Crops to Phenanthrene Stress. Ecotoxicol. Environ. Saf. 2012, 80, 132-139.

(43) Salehi, H.; Chehregani, A.; Lucini, L.; Majd, A.; Gholami, M. Morphological, Proteomic and Metabolomic Insight into the Effect of Cerium Dioxide Nanoparticles to Phaseolus Vulgaris L. under Soil or Foliar Application. Sci. Total Environ. 2018, 616-617, 1540-1551.

(44) Marschner, H.; Römheld, V.; Cakmak, I. Root-Induced Changes of Nutrient Availability in the Rhizosphere. J. Plant Nutr. 1987, 10 (9-16), 1175-1184.

(45) Wang, M.; Zheng, Q.; Shen, Q.; Guo, S. The Critical Role of Potassium in Plant Stress Response. Int. J. Mol. Sci. 2013, 14, 73707390.

(46) Zhao, L.; Hu, Q.; Huang, Y.; Keller, A. A. Response at Genetic, Metabolic, and Physiological Levels of Maize (Zea Mays) Exposed to a $\mathrm{Cu}(\mathrm{OH}) 2$ Nanopesticide. ACS Sustainable Chem. Eng. 2017, 5 (9), 8294-8301.

(47) Yang, J.; Jiang, F.; Ma, C.; Rui, Y.; Rui, M.; Adeel, M.; Cao, W.; Xing, B. Alteration of Crop Yield and Quality of Wheat upon Exposure to Silver Nanoparticles in a Life Cycle Study. J. Agric. Food Chem. 2018, 66 (11), 2589-2597.

(48) Yue, L.; Ma, C.; Zhan, X.; White, J. C.; Xing, B. Molecular Mechanisms of Maize Seedling Response to La2O3 NP Exposure: Water Uptake, Aquaporin Gene Expression and Signal Transduction. Environ. Sci.: Nano 2017, 4 (4), 843-855.

(49) Raes, K.; Knockaert, D.; Struijs, K.; Van Camp, J. Role of Processing on Bioaccessibility of Minerals: Influence of Localization of Minerals and Anti-Nutritional Factors in the Plant. Trends Food Sci. Technol. 2014, 1, 32-41.

(50) Rui, M.; Ma, C.; White, J. C.; Hao, Y.; Wang, Y.; Tang, X.; Yang, J.; Jiang, F.; Ali, A.; Rui, Y.; et al. Metal Oxide Nanoparticles Alter Peanut (Arachis Hypogaea L.) Physiological Response and Reduce Nutritional Quality: A Life Cycle Study. Environ. Sci.: Nano 2018, 5 (9), 2088-2102.

(51) Takeshita, V.; de Sousa, B. T.; Preisler, A. C.; Carvalho, L. B.; Pereira, A. do E. S.; Tornisielo, V. L.; Dalazen, G.; Oliveira, H. C.; Fraceto, L. F. Foliar Absorption and Field Herbicidal Studies of Atrazine-Loaded Polymeric Nanoparticles. J. Hazard. Mater. 2021, $418,126350$. 